\title{
The Thickness Distribution of Oxidation Film on Tapered Pipe Surface in Dieless Drawing
}

\author{
Fang Qin, ${ }^{1}$ Xue-Feng Liu, ${ }^{1}$ and Hao-En Mao ${ }^{1,2}$ \\ ${ }^{1}$ Key Laboratory of Advanced Processing Technology of Materials Ministry of Education, University of Science and Technology Beijing, \\ Beijing 100083, China \\ ${ }^{2}$ School of Materials Science and Engineering, Hebei University of Science and Technology, Shijiazhuang 050018, China
}

Correspondence should be addressed to Xue-Feng Liu, liuxuefengbj@163.com

Received 29 November 2010; Revised 20 February 2011; Accepted 17 March 2011

Academic Editor: Willem J. Quadakkers

Copyright (c) 2011 Fang Qin et al. This is an open access article distributed under the Creative Commons Attribution License, which permits unrestricted use, distribution, and reproduction in any medium, provided the original work is properly cited.

\begin{abstract}
The thickness distribution of oxidation film on the surface of AISI304 stainless steel tapered pipe, its influence factors, and the effect of metal matrix deformation on oxidation behavior during dieless drawing were studied in this paper. The results showed that oxidation rate was affected strongly by induction heating temperature and deformation degree. The thickness distribution of oxidation film was uneven and increased from the larger diameter end to the smaller diameter end along the axial direction of tapered pipe. When induction heating temperature raised or the distance between heat and cold sources was increased, or feed speed was decreased, oxidation rate was accelerated and oxidation film on the tapered pipe surface thickened significantly, due to massive cracks in oxidation film induced by deformation of metal matrix. The density and width of cracks in oxidation film were enlarged, and the thickness of oxidation film increased with the increase in deformation degree.
\end{abstract}

\section{Introduction}

Dieless drawing is a kind of flexible and plastic forming process without conventional dies, which can achieve a great reduction of wire and tube metals in single pass by means of local heating and cooling approach $[1,2]$. Especially, owing to low production cost and high production efficiency, dieless drawing process has good application prospects in the forming process of hard-to-process pipes and wires [3], such as 304 stainless steel tapered pipes. But, oxidation film forms on the heated metal surface in the local heating zone during the deformation process, which not only affects the surface quality but also reduces the anticorrosion performance and service life of products. Therefore, the researches on thickness distribution of oxidation film on tapered pipe surface and its influence factors are of great significance to improve the surface quality of products, optimize process parameters of dieless drawing, and remove oxidation film.

In general, the surface oxidation rate of metal is affected by many factors, such as material compositions, temperature, oxidation atmosphere, and time, and other factors [4-6].
An oxidation film with uniform thickness forms on the metal surface, and the oxidation kinetics curve obeys a linear law, or a parabolic law, or other laws when the metal is heated in a constant temperature and pressure environment [6-10]. As the metal matrix suffered elastic deformation or creep induced by a tensile stress, the surface oxidation film was prone to cracking and brittle rupture because of its worse plasticity, and then oxidation resistance deteriorated and the growth of oxide film was accelerated, thus the oxidation rate was affected severely by stress and deformation of metal $[5,11-13]$. The present studies mostly focused on the growth rules of oxidation film on metal surface when metal suffered elastic deformation or creep of low strain rate at constant temperature. However, oxidation and large plastic deformation occurred at the same time in dieless drawing process of tapered pipes. In addition, deformation degree increased gradually with the increase in the drawing speed, thus geometric boundary of deformation area changed instantaneously and the metal temperature field was transient $[14,15]$. The mechanism of oxidation is complex in dieless drawing process of tapered pipes and has not been reported in literatures. 
TABLE 1: The chemical composition of AISI304 stainless steel.

\begin{tabular}{lcccccccc}
\hline Alloy element & $\mathrm{C}$ & $\mathrm{Mn}$ & $\mathrm{P}$ & $\mathrm{S}$ & $\mathrm{Si}$ & $\mathrm{Ni}$ & $\mathrm{Cr}$ & $\mathrm{Fe}$ \\
\hline wt $\%$ & 0.08 & 2.0 & 0.045 & 0.03 & 1.0 & 10.5 & 18.0 & Other \\
\hline
\end{tabular}

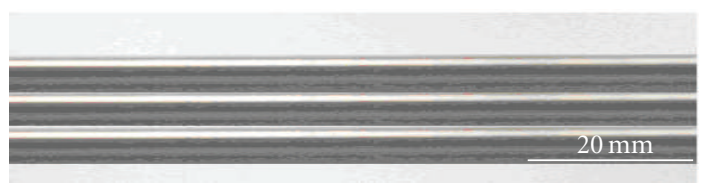

FIGURE 1: The image of AISI304 stainless steel pipes.

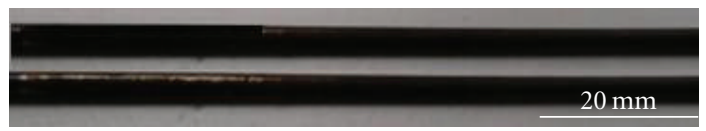

Figure 2: The image of 304 stainless steel tapered pipes after dieless drawing forming.

The influence factors of metal oxide, the thickness distribution of oxidation film on tapered pipes surface, and the effect of process parameters in the dieless drawing process were studied by using AISI304 stainless steel in this paper, for a purpose to provide references for improving surface quality of products and optimizing the parameters of dieless drawing forming.

\section{Experiment}

AISI304 stainless steel pipes of $\Phi 6 \times 1 \mathrm{~mm}$ with a light surface were prepared for dieless drawing as shown in Figure 1, and the chemical composition of AISI304 stainless steel is shown in Table 1.

Tapered pipes with a $0.8^{\circ}$ taper angle were processed by dieless drawing in air. The process parameters were as follows: induction heating temperature 900 to $1100^{\circ} \mathrm{C}$, feed speed 20 to $40 \mathrm{~mm} \cdot \mathrm{min}^{-1}$, the distance between heat and cold sources 15 to $45 \mathrm{~mm}$, drawing speed according to [16] and the section reduction ratio was less than $57 \%$. The profile morphology of oxidation film was observed and the thickness of three points was measured by CAMBRIDGE S360 scanning electron microscope (SEM) and Image Tool such as graphics processing software.

AISI304 stainless steel specimens with a length of $110 \mathrm{~mm}$ were prepared for the following experiments: (1) the pipes were heated to $900^{\circ} \mathrm{C}$ in air, held for $150 \mathrm{~s}$, and then cooled to the room temperature; (2) some specimens were deformed by tension test at $900^{\circ} \mathrm{C}$ in vacuum environment, strain rate $10^{-3} \mathrm{~s}^{-1}$, deformation degree 5 and $10 \%$, respectively, after experiment (1); (3) a part of specimens were reheated to $900^{\circ} \mathrm{C}$ after experiment (2) and held for $150 \mathrm{~s}$, then cooled to the room temperature in air. The section and surface morphologies of the specimens after each experiment were observed by SEM.

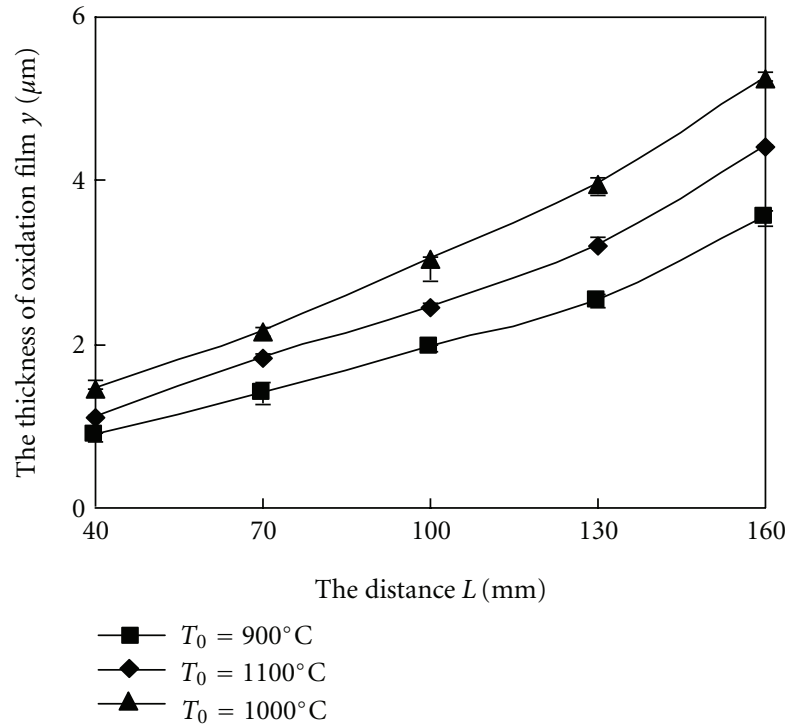

FIGURE 3: Thickness distribution of oxidation film on tapered pipes surface at the different induction heating temperatures.

\section{Results}

After dieless drawing forming, the surface of AISI304 stainless steel tapered pipes was oxidized with generating dark brown oxide, that contains mainly $\mathrm{FeO}, \mathrm{Fe}_{2} \mathrm{O}_{3}, \mathrm{Fe}_{3} \mathrm{O}_{4}$, and $\mathrm{FeCr}_{2} \mathrm{O}_{4}[7,8]$, as shown in Figure 2.

We defined the end of tapered pipe with a largest diameter of $6 \mathrm{~mm}$ as origin. The thickness distributions of oxidation film on the tapered pipe surface are shown in Figure 3, when the feed speed was $20 \mathrm{~mm} \cdot \mathrm{min}^{-1}$, the distance between heat and cold sources $40 \mathrm{~mm}$, the induction heating temperature 900,1000 , and $1100^{\circ} \mathrm{C}$, respectively. Figure 3 indicates that the thickness of oxidation film $(y)$ at the distance $(L)$ of $40 \mathrm{~mm}$ from origin was $0.88,1.11$, $1.46 \mu \mathrm{m}$, respectively, for different heating temperatures. However, when $L=160 \mathrm{~mm}, y=3.55,4.4,5.25 \mu \mathrm{m}$, respectively. The thickness of oxidation film on the surface of tapered pipes increased gradually with the increase in the induction heating temperature, and deformation degree.

Figure 4 shows the effect of the distance between heat and cold sources $\left(S_{0}\right)$ on the thickness of oxidation film, when the feed speed was $30 \mathrm{~mm} \cdot \mathrm{min}^{-1}$, the induction heating temperature $1100^{\circ} \mathrm{C}$, respectively. When $L=160 \mathrm{~mm}, y=$ $3.41,4.24,5.21 \mu \mathrm{m}$ for $S_{0}=15,30,45 \mathrm{~mm}$, respectively. The oxidation film thickened with the increase in the distance between heat and cold sources.

Figure 5 shows the thickness variation of oxidation film at different locations with the increase in feed speed $\left(V_{0}\right)$, when the induction heating temperature was $1100^{\circ} \mathrm{C}$, the distance between heat and cold sources was $35 \mathrm{~mm}$, respectively. In Figure 5, the thickness of oxidation film $y=5.55,4.87,4.38 \mu \mathrm{m}$ at the locations of $L=160 \mathrm{~mm}$, corresponding to $V_{0}=10,20,30 \mathrm{~mm} \cdot \mathrm{min}^{-1}$, respectively. The oxidation film thickened with the reduction in the feed speed. 


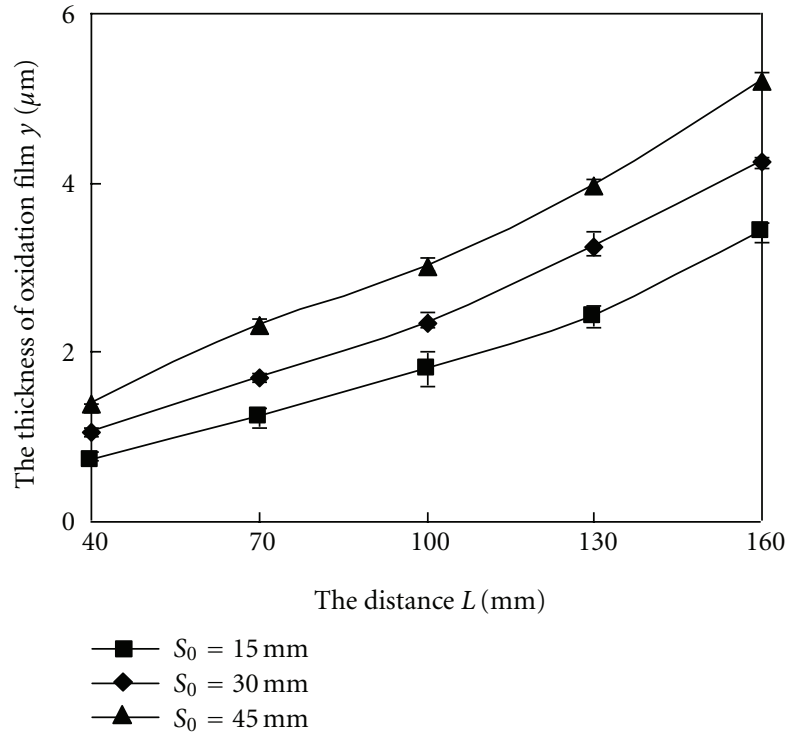

FIGURE 4: Thickness distribution of oxidation film on tapered pipe surface for different the distance between heat and cold sources.

\section{Discussion}

The oxidation degree of metal was affected strongly by temperature, time, and atmosphere [4-6]. The oxidation speeded up and the oxidation film thickened with the increase in the induction heating temperature. The temperature of metal in heating zone and deformation zone rose and the oxidation rate was accelerated, as the induction heating temperature was increased in the dieless drawing process. As a result, the oxidation film on pipe surface thickened when the induction heating temperature was elevated (Figure 3). There was more metal in high temperature zone and the metal stayed longer at high temperature, so that the oxidation film thickened when the distance of heating and cooling sources was increased (Figure 4). This is because that the oxidation film thickens with the oxidation time. Similarly, the pass time of metal through high-temperature zone elongated and the oxidation film thickened, when drawing speed was decreased by reducing feed speed with an identical rate ratio (Figure 5).

In dieless drawing process of AISI304 stainless steel tapered pipes, the oxidation time is shortened with the increase in drawing velocity and tapered pipe length, however, oxidation film thickens, as shown in Figures 3-5. On one hand, the research indicates that oxidation film forms on the heated metal surfaces at high temperature, but the oxidation film blisters and cracks due to inner stress in it, which were found on the surface morphology of oxidation film when AISI 304 stainless steel is heated to $900^{\circ} \mathrm{C}$ without deformation as shown in Figure 6(a). Many tiny channels consist of microcracks in the oxidation film, and oxygen atoms can go through these channels and then react directly with metal matrix, which cause the increase in oxidation rate. On the other hand, the metal suffers a large plastic deformation in the deformation zone during the dieless drawing process, and surface oxidation film is also changed.

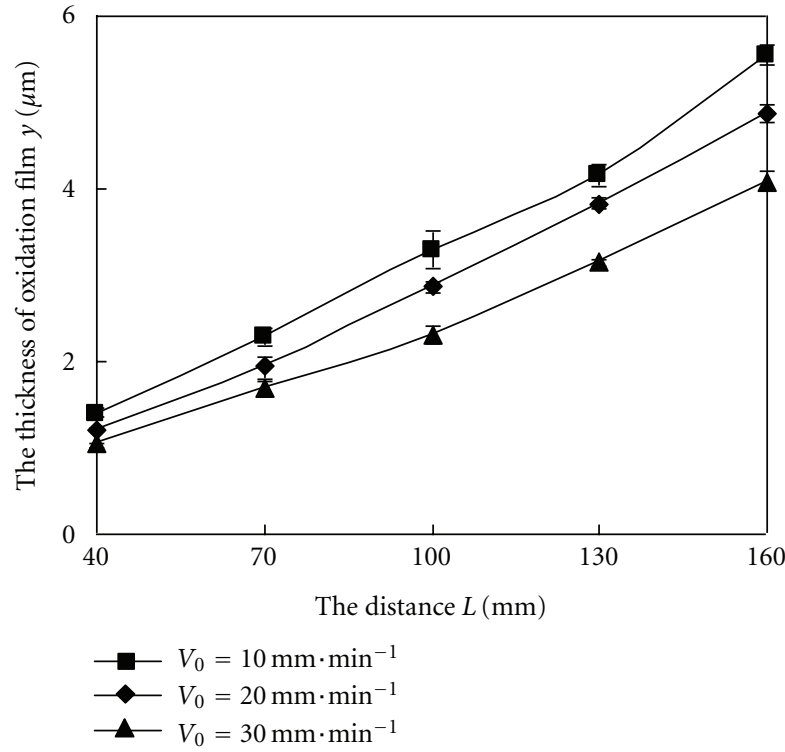

Figure 5: Thickness distribution of oxidation film on tapered pipes surface for different feed speeds.

Figures 6(b) and 6(c) show the surface morphology of oxidation film when the parameters are as follows: the induction heating temperature $900^{\circ} \mathrm{C}$, the deformation degree 5 and $10 \%$, respectively, in vacuum environment. Figure 6 suggests that there are massive cracks and ruptures in the surface oxidation film on the deformed metallic matrix. From the section plans of oxidation film, undeformed oxidation film reveals continuous floe structure(Figure 6(d)), while deformed oxidation film reveals discontinuous mass structure (Figure 6(e)). That indicates that the deformation of metal matrix introduces many ruptures of the oxidation film adhered to it. This is because that the oxidation film prefers brittle rupture due to its low plasticity, and a large amount of cracks are induced, and then the fresh metal surface is revealed, although a certain plastic flow occurs in surface oxidation film along the direction of deformation. However, metal oxidation resistance drops down and new oxidation speeds up rapidly when the fresh metal surface contacts with oxidizing atmosphere directly. Figure $6(f)$ shows the section of surface oxidation film which formed at $900^{\circ} \mathrm{C}$ in air after the deformation in vacuum environment. Due to the existence of many cracks in oxidation film, the thickness of oxidation film formed for a shorter oxidation time during the deformation process is even greater than that generated on the undeformed metal for a longer time, which brings some difficulties to the control and evaluation methods for oxidation degree in the dieless drawing process. By Figures 6(b) and 6(c), it is seen that, the density and width of cracks in oxidation film are enlarged with the deformation degree of metal matrix. As a result, the thickness of new oxidation film increases with the increase in deformation degree. In the dieless drawing process, tapered pipes extend with the raise of the drawing speed and deformation degree, and the thickness of oxidation film increases gradually from the larger diameter end to the smaller diameter end along tapered 


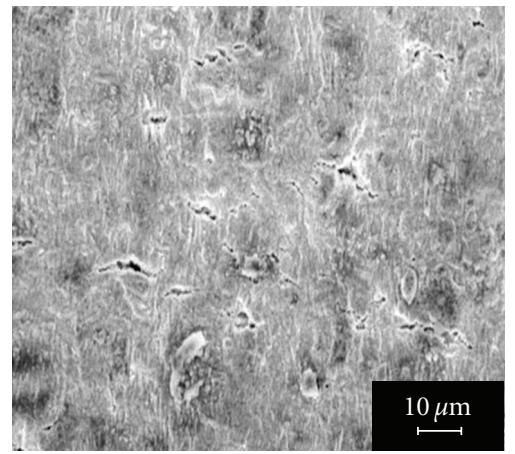

(a)

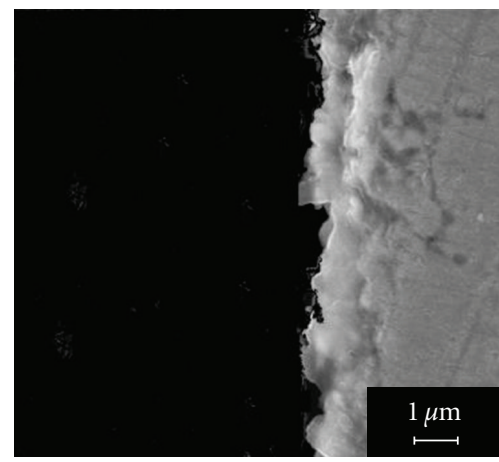

(d)

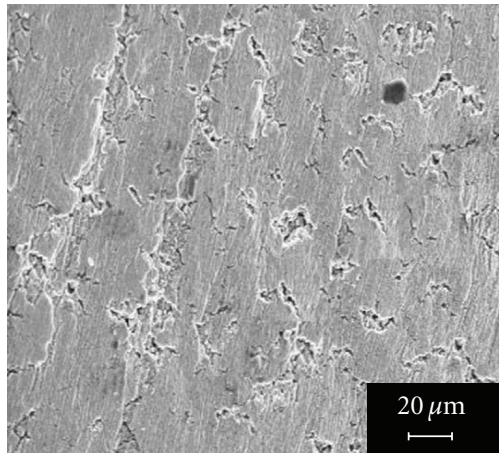

(b)

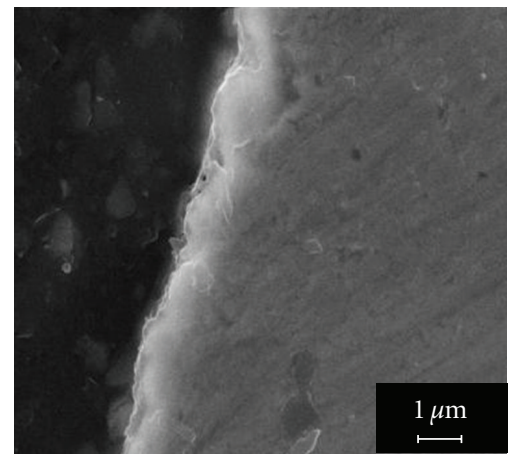

(e)

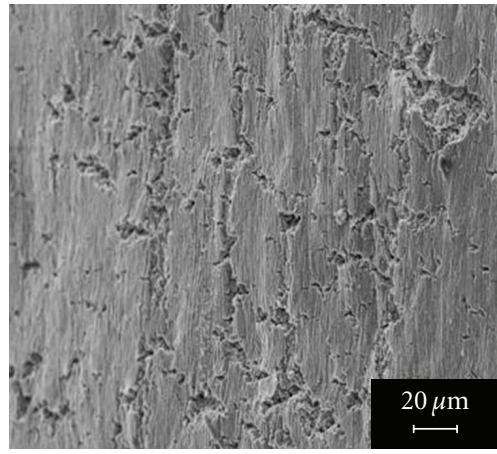

(c)

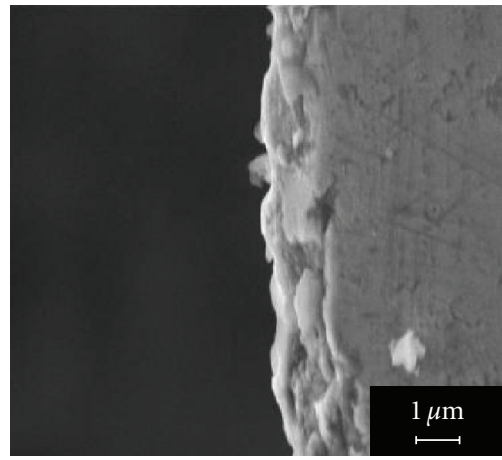

(f)

FIGURE 6: SEM images of oxidation film micromorphology. (a) the surface morphology of oxidation film without deformation and forming at $900^{\circ} \mathrm{C}$ in air; (b) the surface morphology of oxidation film forming at $900^{\circ} \mathrm{C}$ in air, and then deformation degree $5 \%$, strain rate $10^{-3} \mathrm{~s}^{-1}$ at $900^{\circ} \mathrm{C}$ in vacuum environment; (c) the surface morphology of oxidation film forming at $900^{\circ} \mathrm{C}$ in air, and deformation degree is $10 \%$, strain rate $10^{-3} \mathrm{~s}^{-1}$ at $900^{\circ} \mathrm{C}$ in vacuum environment; (d) the section plans of undeformed oxidation film; (e) the section plans of deformed oxidation film; (f) the section of surface oxidation film forming at $900^{\circ} \mathrm{C}$ in air after the deformation in vacuum environment: (i) epoxy resin, (ii) oxide film, and (iii) metal matrix.

pipes. Deformation caused the raise of outer oxidation film thickness and inner oxidation depth. But the influencing mechanism and function mechanism of the applied stress and metallic deformation still need to be researched further.

\section{Conclusions}

The following conclusions were derived from this work.

(1) On tapered pipes surface in dieless drawing process, the thickness of oxidation film distributed unevenly and increased from the larger diameter end to the smaller diameter end along the tapered pipes.

(2) The metal oxidization rate was accelerated, and the oxidation film thickened gradually on the surface of tapered pipes, when the induction heating temperature was raised or the distance between heat and cold sources was extended, or the feed speed was decreased during the dieless drawing deforming.

(3) In the dieless drawing process, the forming of massive cracks in oxidation film induced by deformation of metal matrix was the major cause behind the increase in the oxidation rate and oxidation film thickness.
(4) The thickness of oxidation film increased due to the enlargement of the density and width of cracks in the oxidation film when the deformation degree was raised in the dieless drawing process.

\section{References}

[1] W. Wengenroth, O. Pawelski, and W. Rasp, "Theoretical and experimental investigations into dieless drawing," Steel Research, vol. 72, no. 10, pp. 402-405, 2001.

[2] H. Parvinmehr, G. R. Symmons, and M. S. J. Hashmi, "A non-Newtonian plasto-hydrodynamic analysis of dieless wiredrawing process using a stepped bore unit," International Journal of Mechanical Sciences, vol. 29, no. 4, pp. 239-257, 1987.

[3] Z. T. Wang, S. H. Zhang, Y. Xu, G. F. Luan, and G. R. Bai, "Experiment study on the variation of wall thickness during dieless drawing of stainless steel tube," Journal of Materials Processing Technology, vol. 120, no. 1-3, pp. 90-93, 2002.

[4] X. C. Liu, C. Q. An, Z. X. Cui et al., The Electrochemical Corrosion Mechanism, National Defense Industrial Press, Beijing, China, 2002.

[5] R. Z. Zhu, Y. D. He, and H. B. Qi, High Temperature Corrosion and High Temperature Corrosion Resistance of Materials, Shanghai Scientific and Technical Publishers, Shanghai, China, 1995. 
[6] M. S. Li, High Temperature Corrosion of Metal, Metallurgy Industry Press, Beijing, China, 2001.

[7] N. Karimi, F. Riffard, F. Rabaste et al., "Characterization of the oxides formed at $1000^{\circ} \mathrm{C}$ on the AISI304 stainless steel by X-ray diffraction and infrared spectroscopy," Applied Surface Science, vol. 254, no. 8, pp. 2292-2299, 2007.

[8] J. G. Peng, S. Z. Luo, and M. Yuan, "Research on oxidation behavior of 304 austenitic stainless steel at high temperature," Baosteel Technology, no. 4, pp. 29-32, 2007.

[9] L. Jian, P. Jian, H. Bing, and G. Xie, "Oxidation kinetics of Haynes 230 alloy in air at temperatures between 650 and $850^{\circ}$ C," Journal of Power Sources, vol. 159, no. 1, pp. 641-645, 2006.

[10] Z. M. Yang, J. T. Han, J. Liu, and B. Liu, "Study on oxidation resistance of $310 \mathrm{~S}$ austenitic stainless steel," Hot Working Technology, vol. 35, no. 14, pp. 33-34, 2006.

[11] Y. H. Qian, M. S. Li, and Y. M. Zhang, "A review on high temperature oxidation of alloys under mechanical loading," Corrosion Science and Protection Technology, vol. 13, no. 6, pp. 342-346, 2001.

[12] R. Rolls and M. H. Shahhosseini, "Simultaneous creep and oxidation of Fe-Si alloys at 973-1073 K," Acta Metallurgica, vol. 30, no. 8, pp. 1503-1510, 1982.

[13] J. H. Ke and J. P. Tu, "High temperature oxidation behavior of Fe3Al based alloy," Journal of the Chinese Society of Corrosion and Protection, vol. 20, no. 1, pp. 27-28, 2000.

[14] Z. T. Wang, G. F. Luan, G. R. Bai, K. Kobatake, and H. Sekiguchi, "A mathematical model study on the die-less drawing of variable-section tubular parts," Journal of Materials Processing Technology, vol. 59, no. 4, pp. 391-393, 1996.

[15] H. Q. Zhang, H. Y. Xia, and S. L. Chen, "Study on forming test and numerical analysis on temperature field in drawing without die," Metal Forming Machinery, no. 2, pp. 38-42, 1999.

[16] H. E. Mao, X. F. Liu, F. Qin, Y. He, and J. X. Xie, "Theoretical and experimental analyses of a speed control model for continuous dieless drawing process of tapered pipes," Journal of University of Science and Technology Beijing, vol. 32, no. 5, pp. 610-615, 2010. 

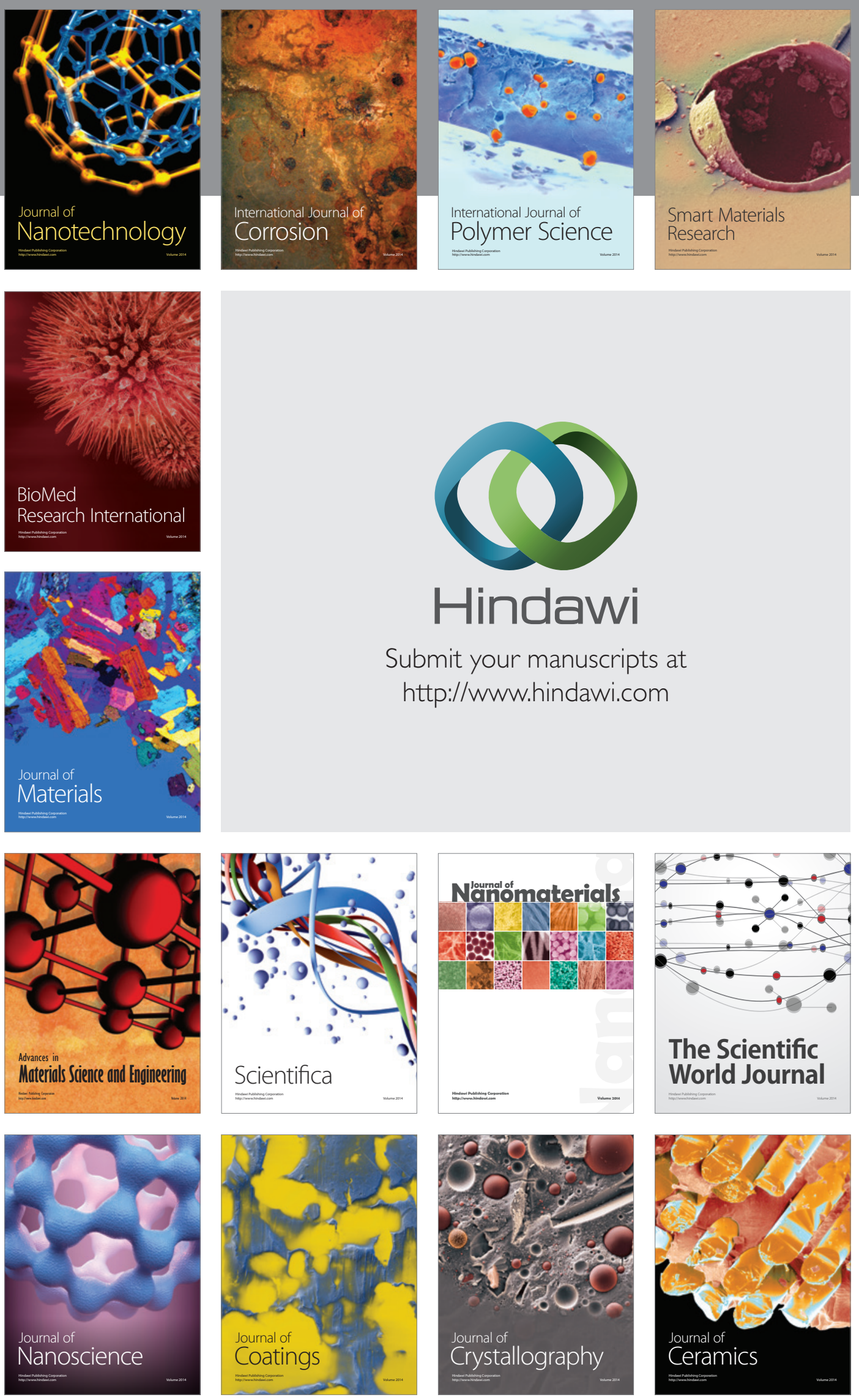

The Scientific World Journal

Submit your manuscripts at

http://www.hindawi.com

\section{World Journal}

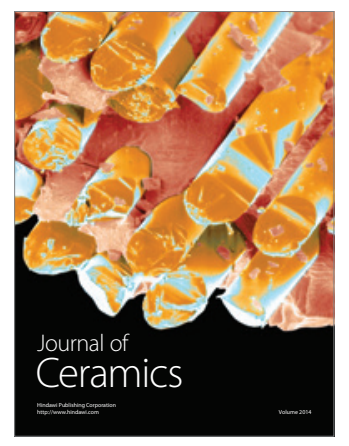

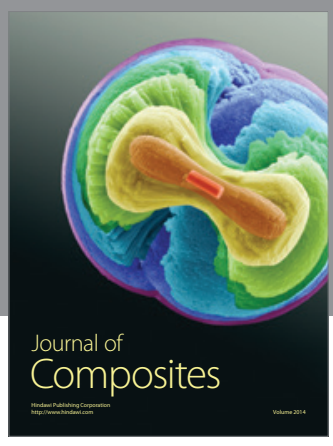
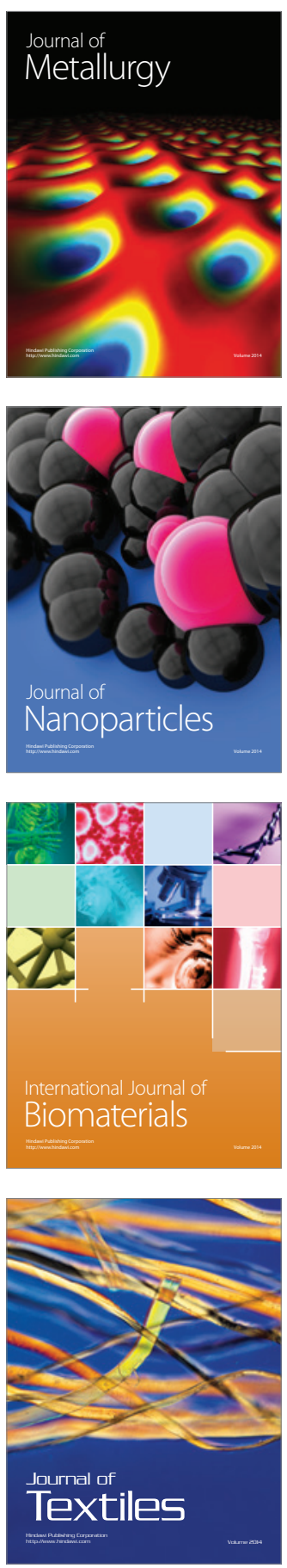